\title{
EFFECTS OF VEGETATION ON RADON TRANSPORT PROCESSES IN SOIL
}

\author{
Progress Report
}

for Period November 1, 1989 - October 31, 1990

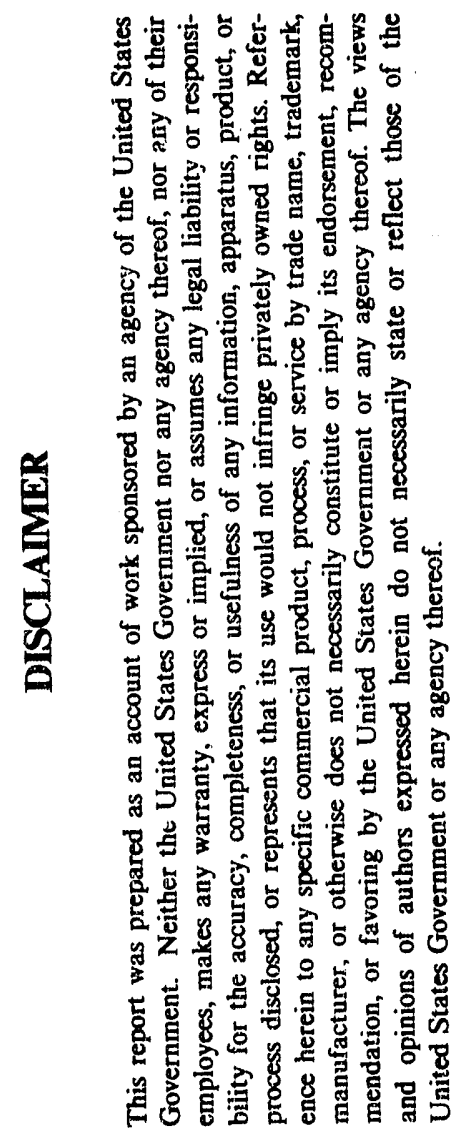

T.B. Borak

Colorado State University

Fort Collins, Colorado 80523

February 1991

Prepared for

THE U.S. DEPARTMENT OF ENERGY AGREEMENT NO. DE-FG02-87ER60581 


\section{PROGRESS REPORT}

\section{Outdoor Data}

Radon concentrations in soil gas were measured on a weekly schedule. Samples were extracted through the tubes used for measuring pressure differentials at depths of $30,100,180 \mathrm{~cm}$. Figure 1 shows the average radon gas concentration near the structures for the time period November 1989 - August 1990. The sample uncertainty based on counting statistics is approximately equal to the dimensions of the circular symbols.

From November to March, the concentrations increase with depth and are for the most part constant over time. The situation is similar from May through August. There is a pronounced increase in the soil radon concentration in early March. This is followed by a decrease to pre March levels at $30 \mathrm{~cm}$. However, at 100 and $180 \mathrm{~cm}$ the radon concentrations remain elevated.

Attempts were made to explain this data. The average soil moisture content measured with the neutron gauge are shown in Figure 2. Also shown is a history of precipitation events. The period from November to March was relatively dry. On March 6 there was a heavy rain that deposited $3 \mathrm{~cm}$ of water. This was followed by a snow storm that contained over $5 \mathrm{~cm}$ of moisture. Precipitation events during the summer months did not seem to have a large effect on the moisture profile because these rainfall events are typical of short duration with a large amount of runoff.

Other soil parameters and meteorological data were analyzed in order to determine their influence on soil radon concentrations. Figure 3 includes a plot of soil temperature at $100 \mathrm{~cm}$ along with moisture and radon concentrations. Although the sample frequency was not sufficient to permit extensive quantitative analysis, a stepwise 
regression procedure was used to identify linear correlations between these variables. At every depth, moisture was the dominating factor. It accounted for $60 \%, 80 \%$ and $90 \%$ of the variance in radon concentrations at 30,100 and $180 \mathrm{~cm}$ deep. Barometric pressure was not included in this analysis since a soil sampling frequency of one per week could not be compared to a single value of barometric pressure which has many high frequency components with periods less than one day.

\section{Indoor Data}

Figure 4 is a plot of monthly arithmetic mean radon concentrations in one structure from January 1989 - August 1990. The error bars represent the standard deviation of the sample of 15 minute measurements used to obtain the monthly average. The sample size was always more than 2000 and the uncertainty in the estimate of the mean was within the dimensions of the circular symbol.

The monthly average concentrations range from $700-1200 \mathrm{~Bq} \mathrm{~m}^{-3}\left(20-30 \mathrm{pCi}^{-1}\right)$. The closed circles represent periods of time when all access tubes and ports were closed. The open circles represent times when all 190 ports were open creating a communication area of $24 \mathrm{~cm}^{2}$ directly to the soil. The vertical arrow indicates the time of the heavy precipitation that influenced the soil conditions discussed above. It is interesting that the monthly averaged data does not show dramatic temporal variations.

Figure 5a shows the daily averaged radon concentration for the period of time just preceding and following the March precipitation event. There are temporal variations, but nothing that indicates a peculiarity on March 6-7. Figure 5 b-c shows plots of indoor-outdoor temperature differences and barometric pressure. A stepwise linear 
regression using meteorological data indicates that for this time period outdoor ternperature was the most important factor in describing the variability of indoor radon concentrations with time. Similar results were obtained for other time periods, but the influence of temperature was not always as pronounced.

The indoor radon concentrations depend on radon entry rate and mean residency time which is controlled by the natural ventilation rate. The ventilation rate was determined continuously using a constant source of trace gas and an infrared spectrophotometer. Figure $6 \mathrm{a}$ is a plot of daily averaged ventilation rate, $\mathrm{hr}^{-1}$, as a function of time from February 27 to March 21, 1990. If the radon concentration and ventilation rate are known, it is possible to estimate the radon entry rate, $\mathrm{kBq} \mathrm{h}^{-1}$. The radon entry rate is shown in Figure $6 \mathrm{~b}$. Figure $6 \mathrm{c}$ also shows the daily averaged wind speed during this period. There is a strong visual correlation between these three variables. It appears that when wind speed is high, the radon entry rate increases. Figure $6 \mathrm{~d}$ shows the indoor radon concentration vs. time. It can be seen that for high radon entry rates, the radon concentration actually decreased. This is because of the corresponding increase in the ventilation rate during this period.

In order to explore the dynamics of this situation, it is required to analyze the data in detail greater than that permitted by monthly or daily averages. Figure 7a shows plots of 15 minute averaged wind speed vs. time. Figure $7 \mathrm{~b}$ shows the pressure differences vs. time between inside of the structure and a point located in the soil at $1 \mathrm{~m}$ depth and $0.3 \mathrm{~m}$ from the south wall. Figure $7 \mathrm{c}$ shows the inside-outside pressure differential vs time. There is a clear dependence of both soil and outdoor pressure 
differences with wind speed. Figure 8a shows a plot of pressure difference and wind speed for a location $1.8 \mathrm{~m}$ depth and $0.3 \mathrm{~m}$ from the south wall. There is a quadratic relationship indicating that pressure differences between the soil and indoor are a function of wind speed squared. Figure $8 \mathrm{~b}$ shows a similar situation for a soil location 1 meter below the surface and 0.3 meter from the south wall. It can be seen that the pressure differences are resolved into two curves. The lower curve indicates a larger pressure difference when the wind is blowing from the south compared to that where the wind is blowing with the same speed from the north. Attempts to include other meteorological parameters as predictors of pressure differences were unsuccessful.

Figure 9 is a plot of indoor radon concentrations vs pressure differences. There is no obvious correlation between these two variables. However, in Figure 6 we observed that the radon entry rate increased with wind speed and from Figure 7 we concluded that wind speed increased the pressure difference between the soil and indoors. Thus, the high values of radon entry are associated with wind generated pressure differentials. There is also however a persistent, but slower radon entry rate that occurs even when there is little or no wind. It is interesting that the highest indoor radon concentrations are observed when the radon entry rate is low.

To uncierstand the driving force responsible for the slow radon entry, the structure was modified to include a variable speed fan in the door. The fan speed was selected to intentionally pressurize the holıse. Figure 10a shows the pressure differentials between outdoors and two soil locations at different depths beneath the surface under normal conditions. Figure $11 \mathrm{~b}$ shows the same pressure differentials when the fan was 
operational. The fan clearly pressurized the structure except for periods of large wind speeds where there were negative pressure excursions.

The radon entry rate was determined for these conditions. In order to examine the constant term, radon entry rate was computed and averaged only when the wind speed was less than $1 \mathrm{~m} \mathrm{~s}^{-1}$. The data are summarized in Table II.

When the fan was off, the natural ventilation rate was less than $0.1 \mathrm{hr}^{-1}$ for periods of little or no wind. The indoor-outdoor pressure differentials were consistent with zero and the structure was negative with respect to the soil at a depth of $1 \mathrm{~m}$. The combined radon entry rate for these conditions was $0.9 \pm 0.1 \mathrm{kBq} \mathrm{hr}^{-1}$. When the fan was operational, the ventilation rate increased to $0.3 \mathrm{hr}^{-1}$. The structure was positive with respect to both outdoors and soil. The radon entry rate corresponded to $0.8 \pm 0.1$ $\mathrm{kBq} \mathrm{hr}{ }^{-1}$. These two numbers are indistinguishable.

The effective leakage area was determined according to the methods described by Sherman, 1980. For the induced pressure differences indicated in Table II, the computed leakage area was approximately $30 \mathrm{~cm}^{2}$. This is considerably smaller than values quoted for houses. However, in the latter cases much higher pressure differences are used.

During the month of January 1991 we have improved our methods of determining building dynamics. The entry doors were modified to accept fans and tubes to provide laminar flow that is used to pressurize or depressurize the structures in a systematic manner. The system has been installed and calibrated so that leakage area can be determined routinely. 
The salient features of the data obtained thus far are as follows:

- Radon gas concentrations in the silty clay surrounding the structures increased with depth. However, there are no apparent "seasonal" variations. The most important factor accounting for the variability of radon in soil is moisture which was dominated by a single precipitation event. Moisture changes the soil conditions such that a simple one dimensional diffusion model cannot be used to describe long term transport from soil gas to the atmosphere.

- Monthly averaged radon concentrations in the underground structures do not exhibit obvious seasonal variations. This is somewhat contradictory to that observed in published radon surveys. However, it might indicate that the lifestyle or demands of the occupants control indoor concentrations rather than the physical driving forces responsible for radon transport and entry. A stepwise multiregression model indicates that when no attempt is made to control indoor temperature, outdoor temperature is the best predictor of daily average Rn concentration. However, this generally accounts for less than $50 \%$ of the day to day fluctuation.

- Indoor radon concentrations are not correlated with pressure differences between the structure and surrounding soil.

- For these structures the radon entry rate has two components; one that is constant and the other that changes with time. The time dependent component is correlated with pressure differentials that are principally 
generated by wind speed and direction. Thus, as the wind speed increases, the radon entry rate increases. For periods of low wind speed the constant radon entry term dominates. This term remains constant even when the basement is pressurized by $0.5 \mathrm{~Pa}$ with respect to the surrounding soil. It can be responsible for more than $50 \%$ of the total radon entering the structures.

- The wind speeds that increase the radon entry rate, also increase the ventilation rate. For these structures the increased ventilation compensates for the increased radon input. Thus the periods of highest indoor concentration occur when the radon entry rate is low.

\section{QUALITY ASSURANCE}

For the month of December 1990 the routine data acquisition was interrupted. During this time all detectors and instrumentation were calibrated and intercompared. This quality assurance program enabled us to tune the instrumentation and proceed in performing future experiments with confidence. 


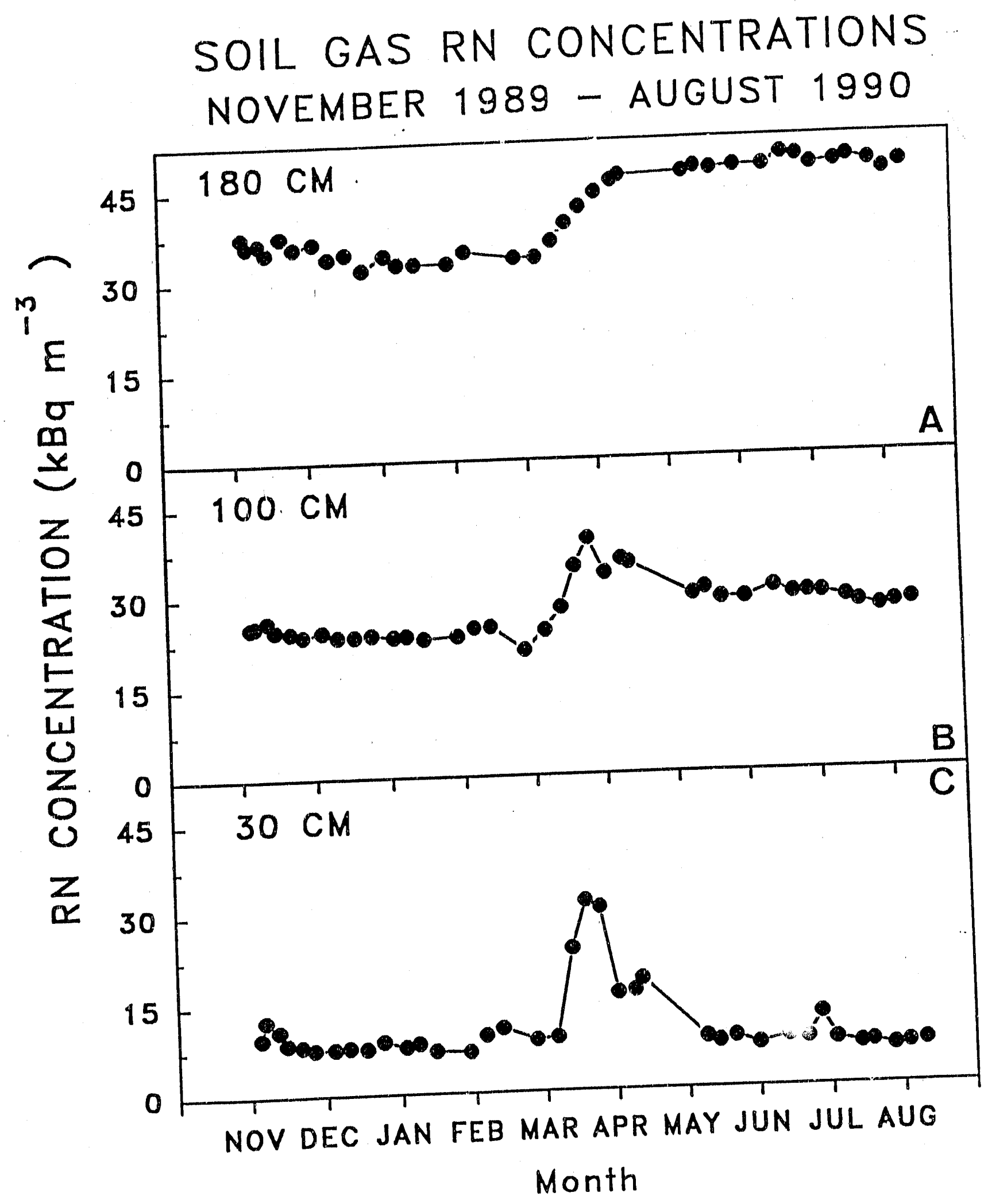

Figure 1 


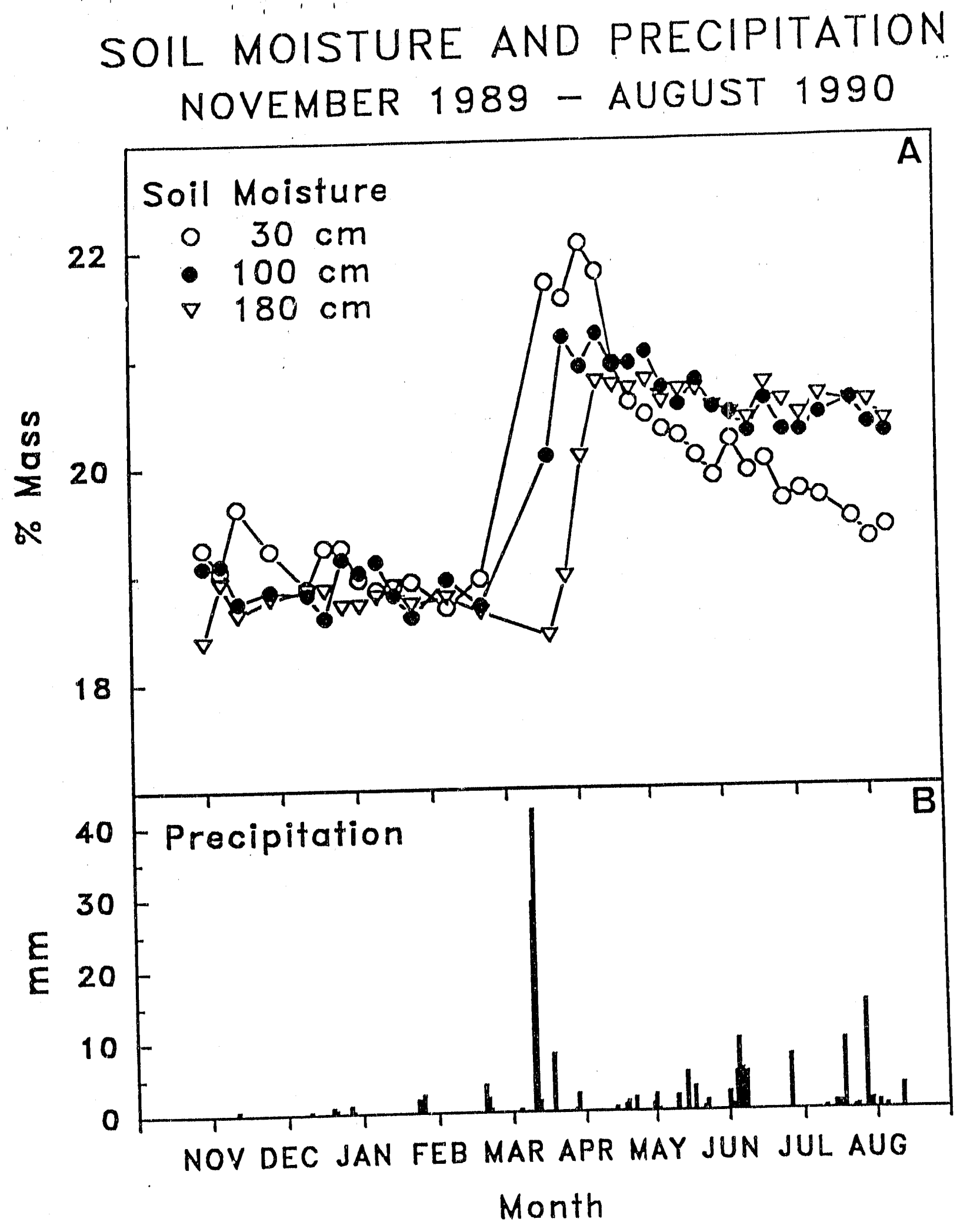

Figure 2 


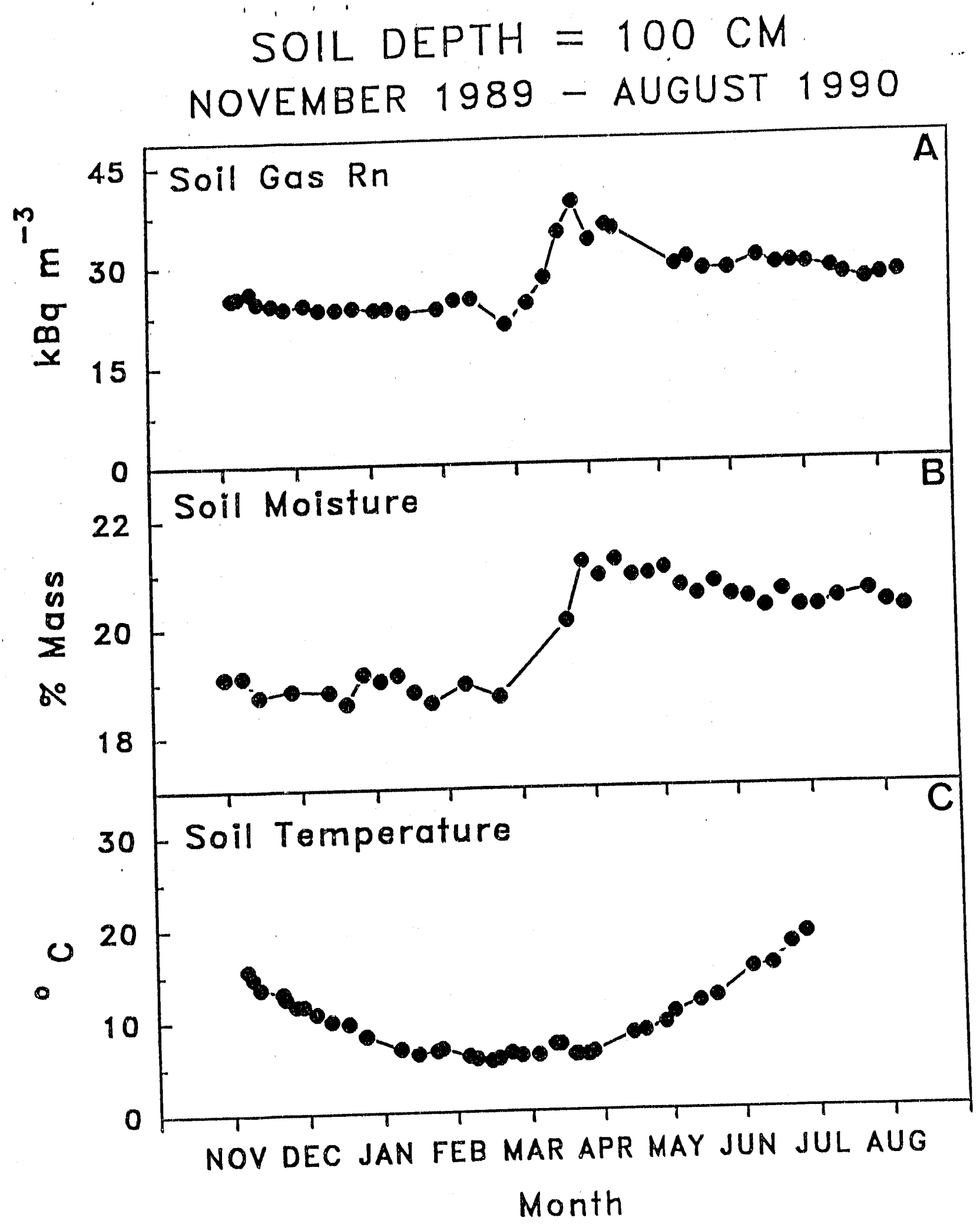

Figure 3 


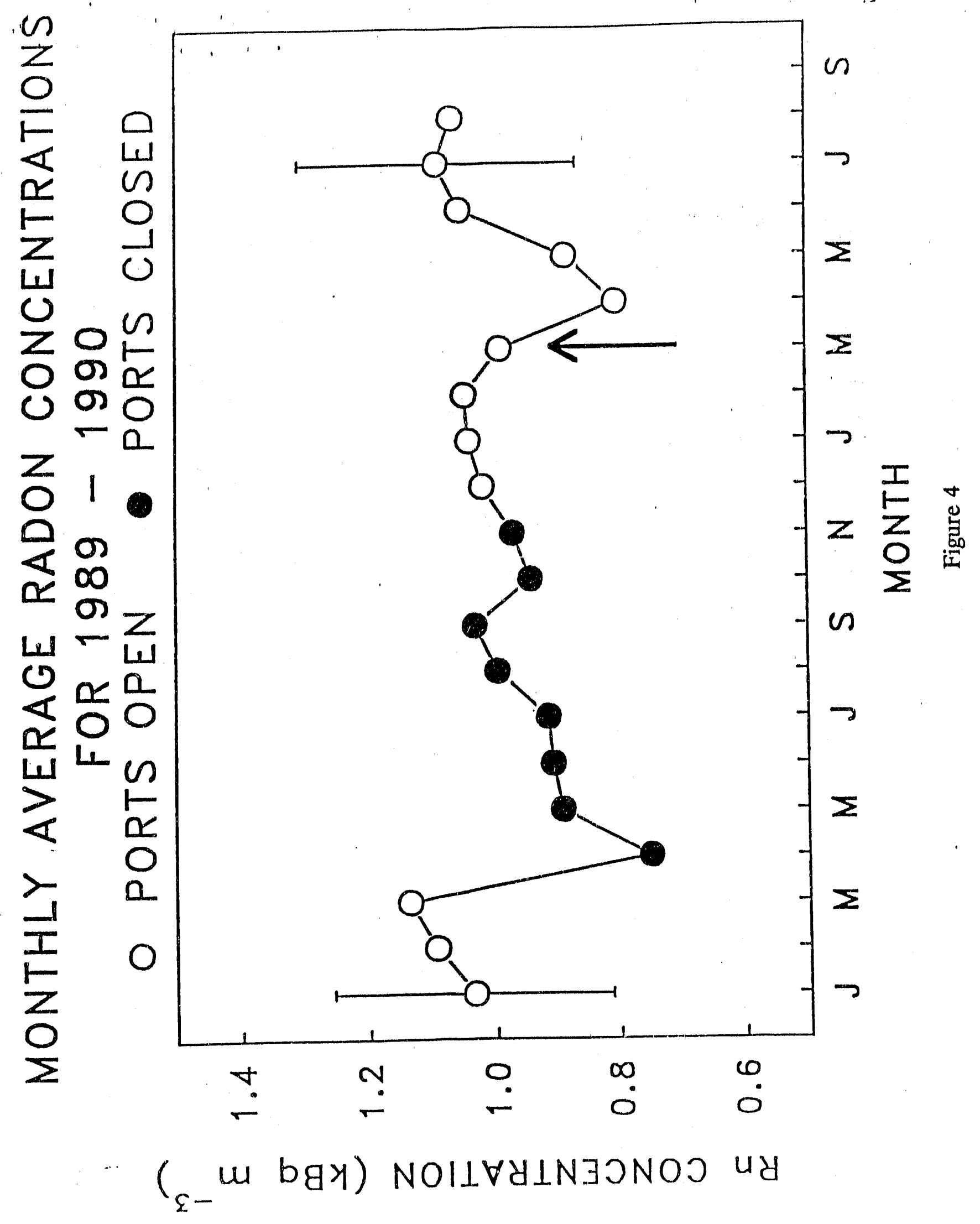




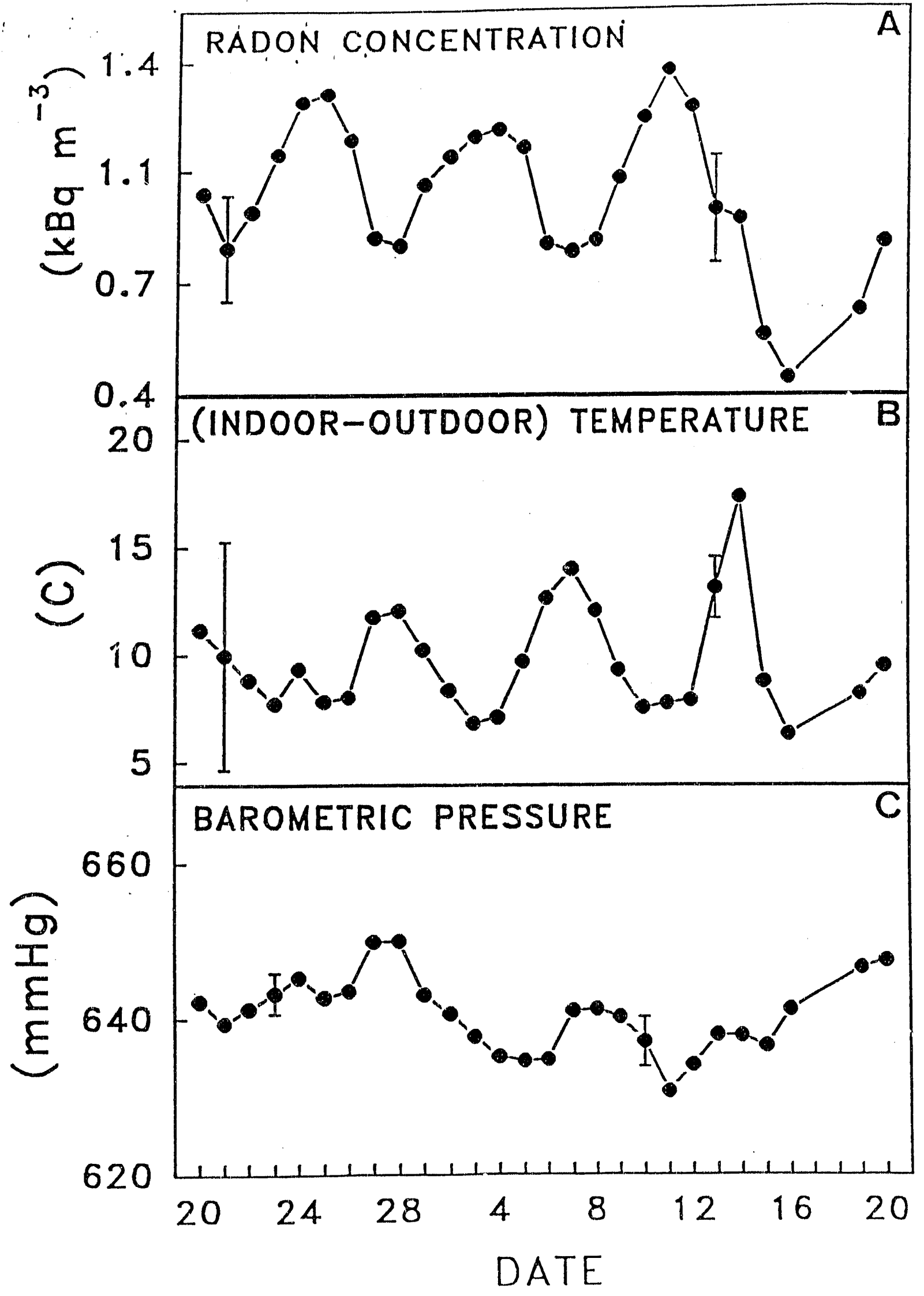

Figure 5 


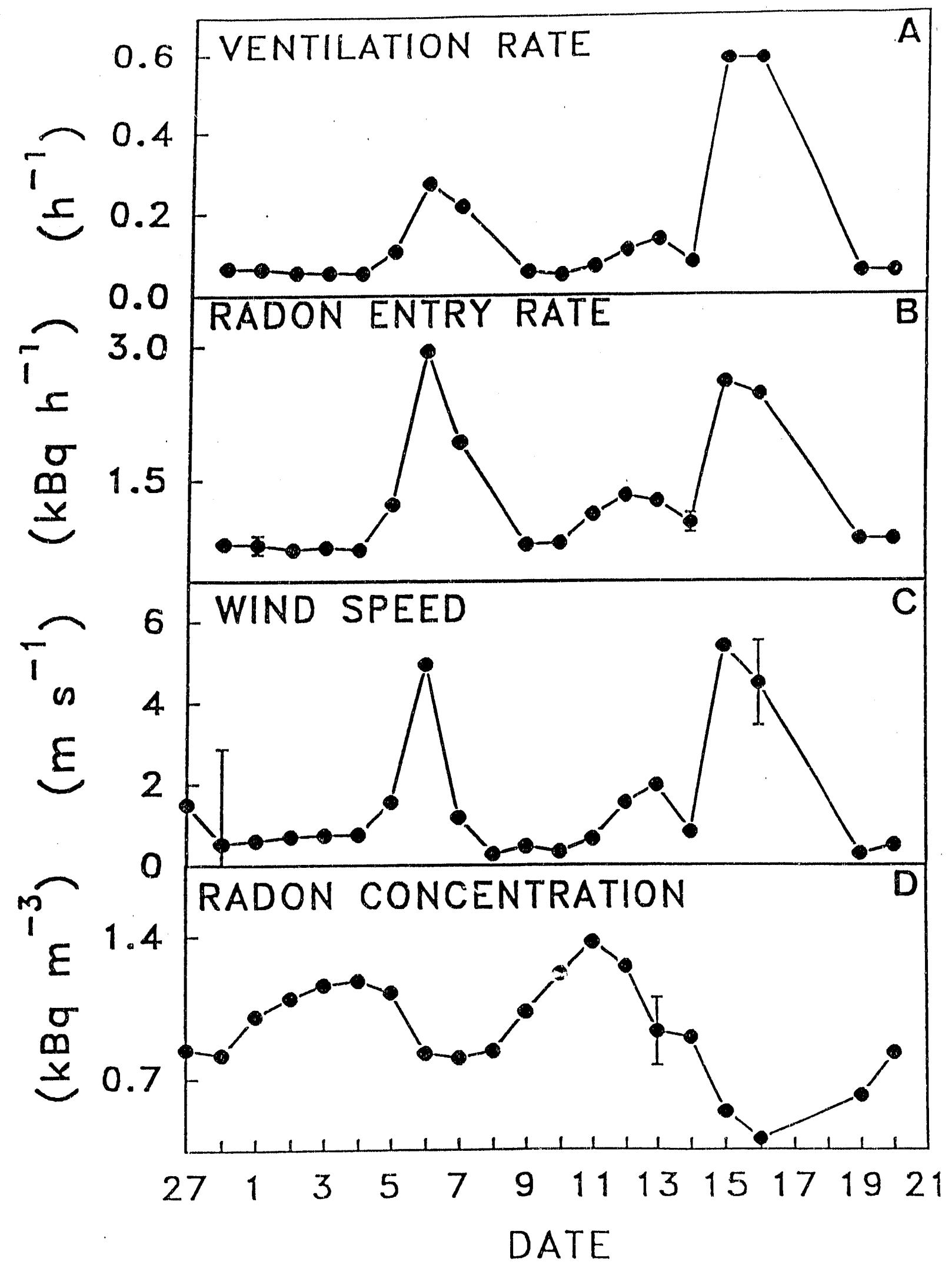

Figure 6 


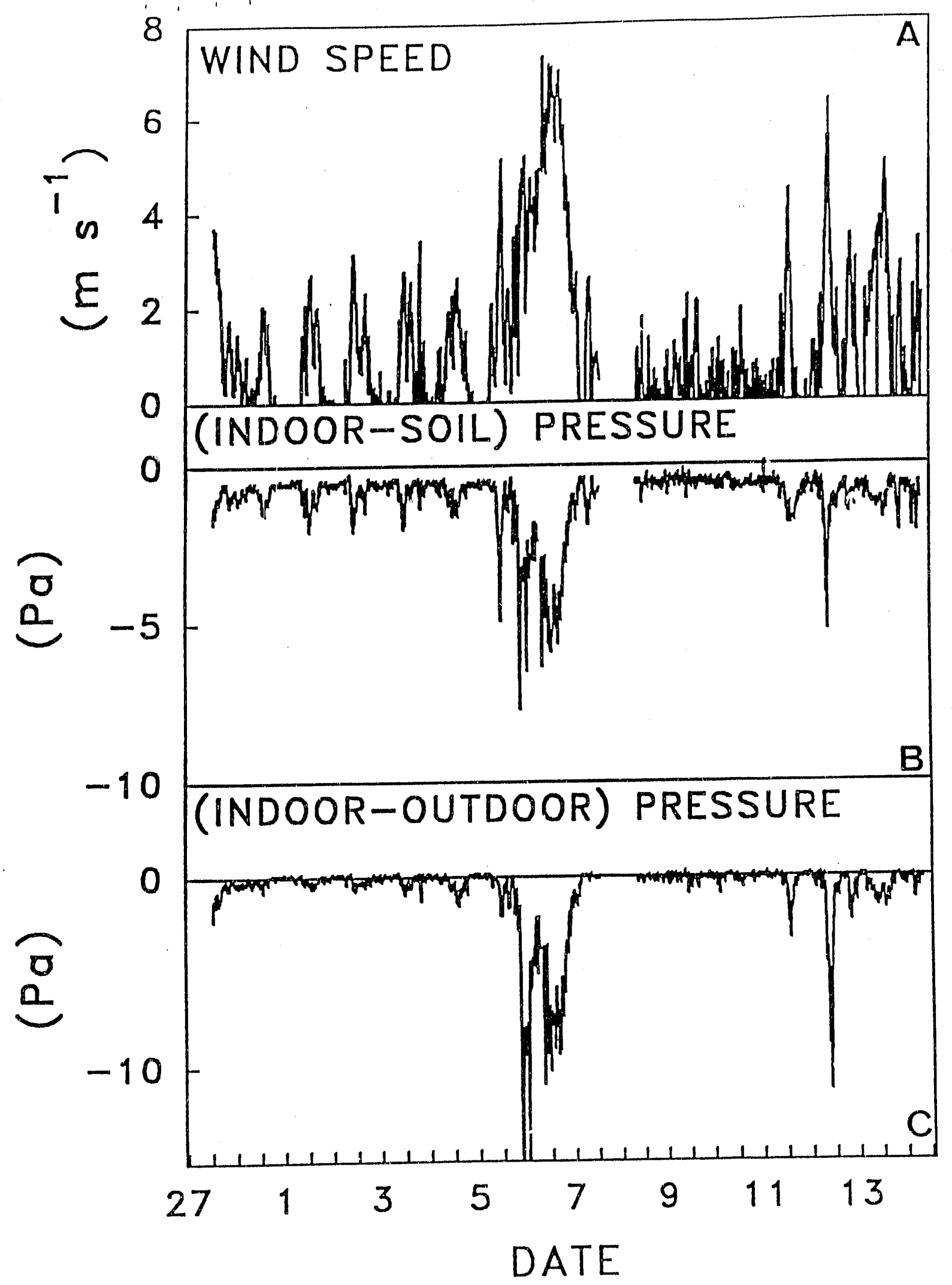

Figure 7 


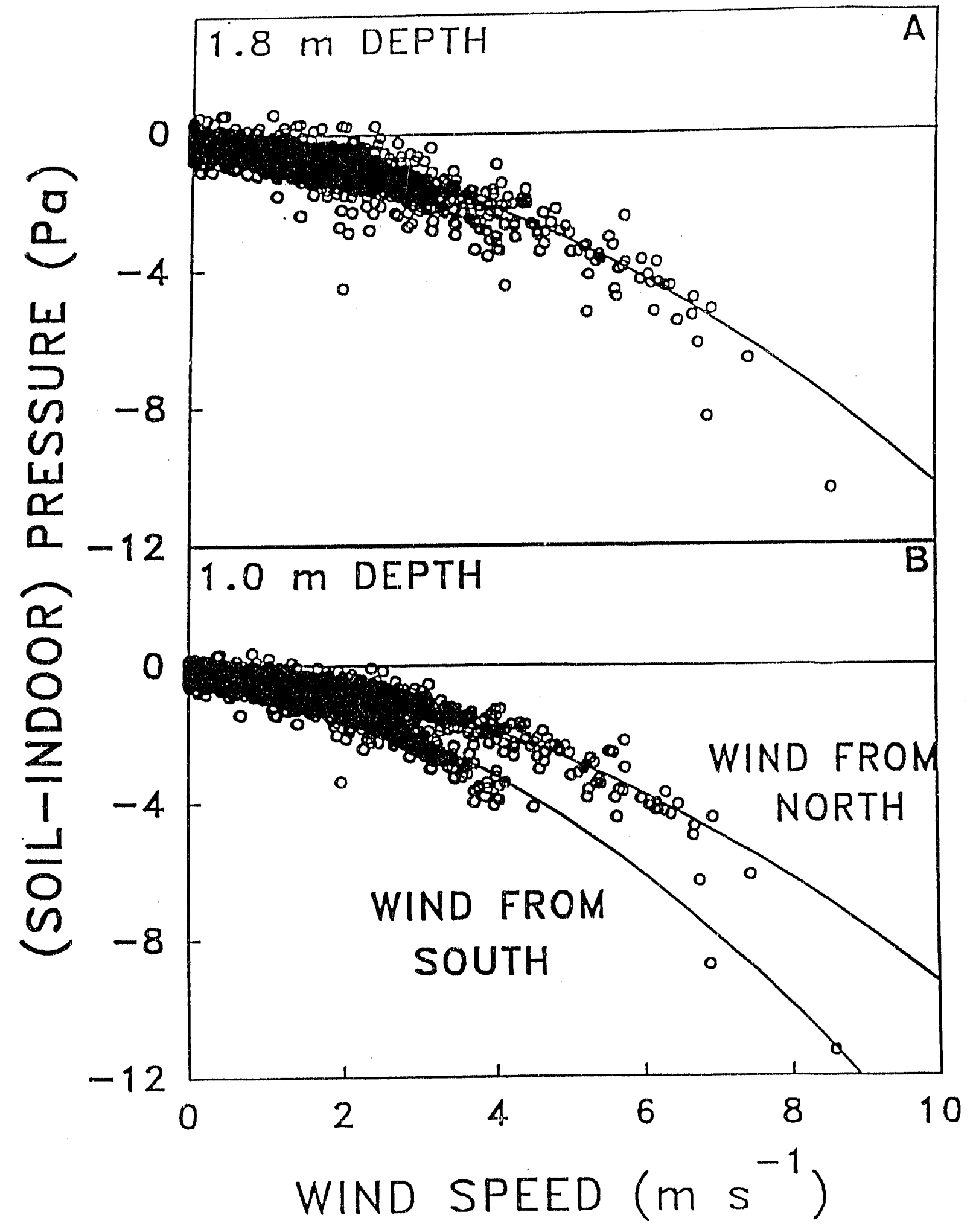

Figure 8 


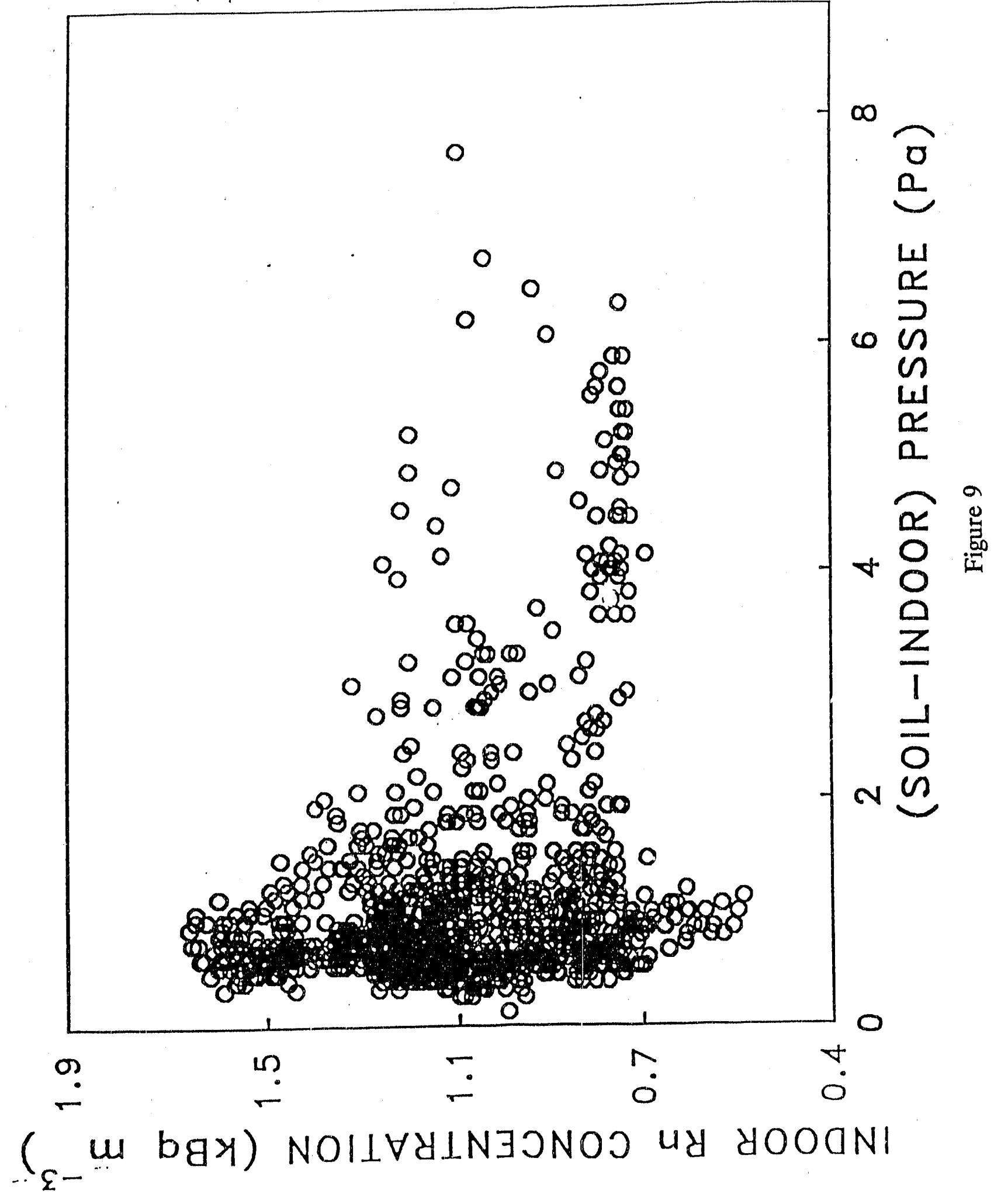




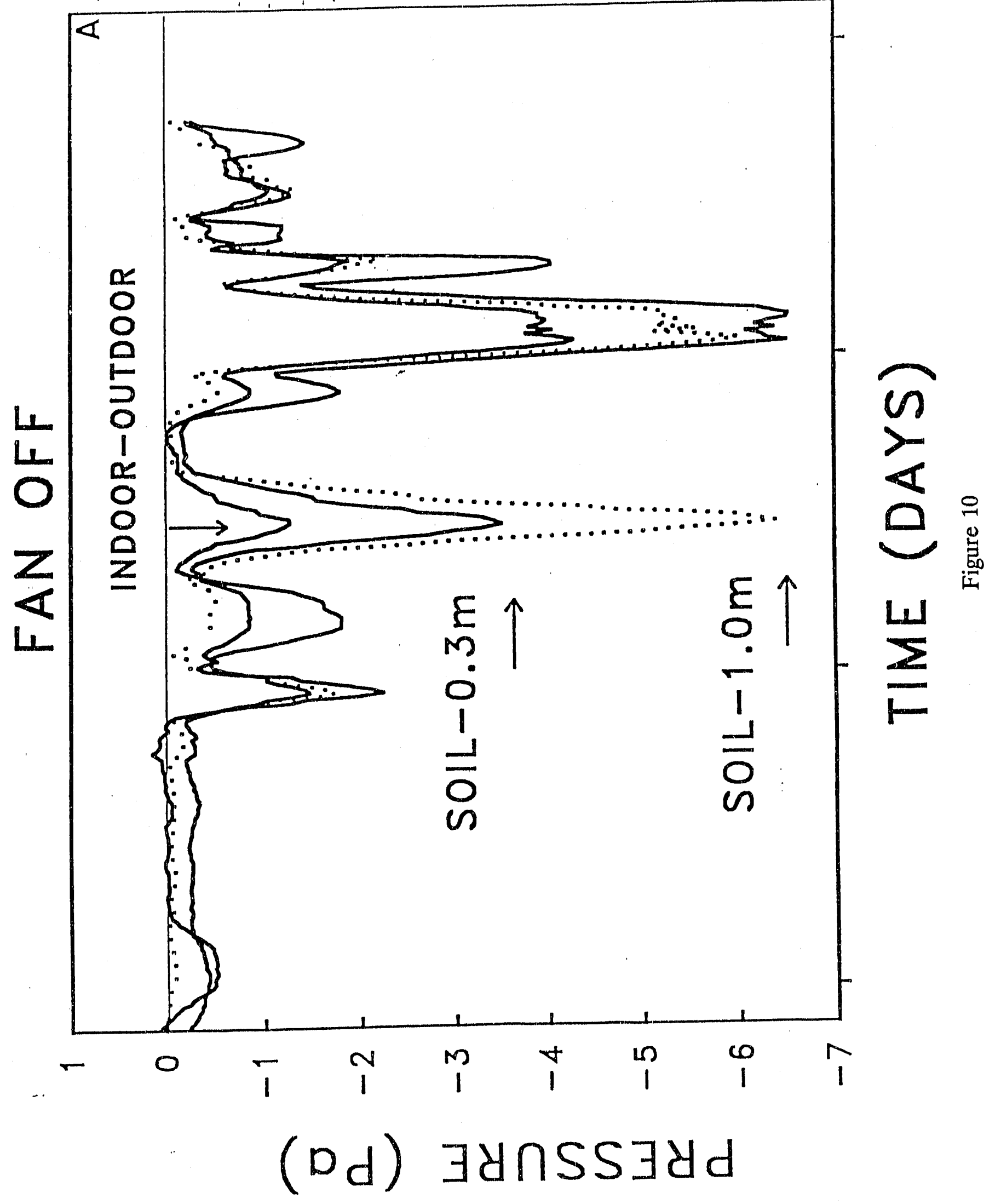




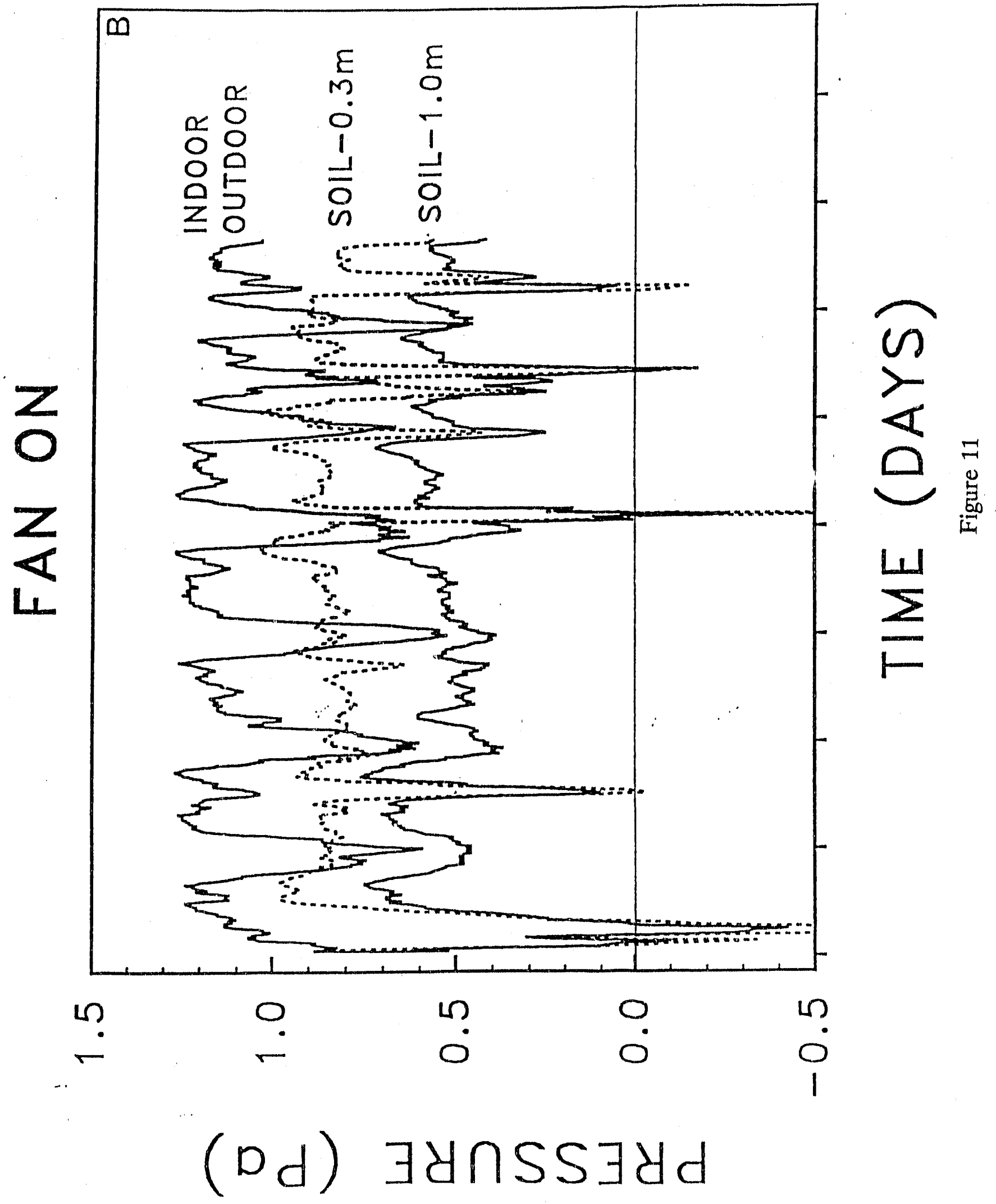




\section{FUTURE STUDIES}

The following experiments will be performed during the next budget period. The objectives are to isolate the components of radon entry and characterize soil properties before vegetation is introduced during the last budget period.

- Begin weekly measurements of soil permeability using the same locations currently used to determine pressure differentials. This will include measurement vs depth and distance from the structures.

- Determine the influence of wall-floor joints on radon entry. We will install a plastic molding in one structure that will seal the joint and also permit us to sample radon levels in this region. Radon concentrations and entry rates will be compared with the other structure that will not have the plastic barrier installed.

- Measure radon entry through the concrete walls and floor with flux accumulators. These will be placed both below and above ground level to determine influence of soil plus concrete and concrete alone.

- Obtain 3-D radon transport computer code developed by PNL. This will be used to separate convective flow from diffusion. The code will be tailored to our computer system and a graphics visualization routine will be written to insure that the geometrical configurations are modeled properly. This work will proceed in collaboration with Dr. Peter Owczarski at PNL (see attached letter).

- Determine sources and entry rates of indoor thoron using instrumentation developed at New Mexico Institute of Mining and Technology. This work will proceed in collaboration with Dr. Stephen Schery (see attached letter). 
- Determine effects of solar heating and near surface evaporation as a driving mechanism for radon transport. This work will be formed in collaboration with Dr. M. Reimer with the U.S. Department of Interior. (See attached letter)

- Determine effects of precipitation events on radon transport and entry. This will be performed by irrigating the soil near one structure while the second structure serves as a control. An automatic sprinkling system has already been installed. 


\section{APPENDIX A}

\section{List of Manuscripts}

Borak, T.B., Whicker, F.W., Fraley, L., Gadd, M.S., Ibrahim, S.A., Monette, F.A., Morris, R., Ward, D.C., CHARACTERIZATION OF RADON ENTRY RATES AND INDOOR CONCENTRATIONS IN UNDERGROUND STRUCTURES.

Twenty-ninth Hanford Symposium; "Indoor Radon and Lung Cancer: Reality or Myth?"

Ward, D.C. and Borak, T.B., DETERMINATION OF TIME VARYING ${ }^{222}$ RN CONCENTRATIONS USING FLOW THROUGH SCINTILLATION FLASKS. Submitted for publication in Health Physics Journal.

Monette, Frederick A., VARIATIONS OF ${ }^{222}$ RN CONCENTRATIONS IN SOIL GAS AT A SITE IN THE SEMIARID WESTERN U.S., M.S. Thesis, Colorado State University, 1990. 
$\therefore \quad, \quad, 1,1$,

\section{APPENDIX B}

Letters of intent to perform joint studies at the Colorado State University Radon Facility 


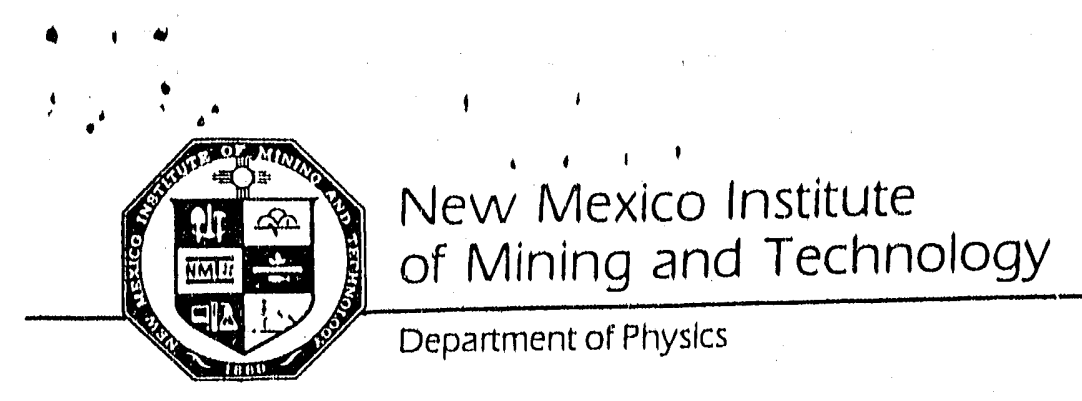

Socorro, NM 87801

December 7, 1990

Dr. Tom Borak

Colorado State University

Dept. of Radiation Biology

Fort Collins, CO 80523

Dear Tom:

Thanks for your letter of 25 october 1990 and the draft of the paper presented at the Hanford symposium. you asked for suggestions for collaborative work and recommendations for future use of the facility.

An important, and relatively cost-effective, project would be for us to bring up our continuous thoron monitor for several weeks. A graduate student working with me, Yanxia Li, is modeling the sources of indoor thoron for her Ph.D. dissertation. Your facility already has in place $90 \%$ of the auxiliary instrumentation we need. We'd want to get data for several different indoor pressure regimes and perhaps collect soil samples. Consider this a request to use your facility although with our present work load it would likely be spring or later before we could come up.

My second suggestion is that before too long you should proceed with your vegetation studies. I think your project is about the only DOE program in a position to systematically investigate the effects of vegetation on soil permeability, radon diffusion, and radon entry. I expect you'll find some interesting results and urge you to keep an open mind about their interpretation. study of: the interaction between vegetation, soil moisture, and radon transport alone is sufficient justification to proceed with this phase of the project.

Have a happy holiday.

cordially,

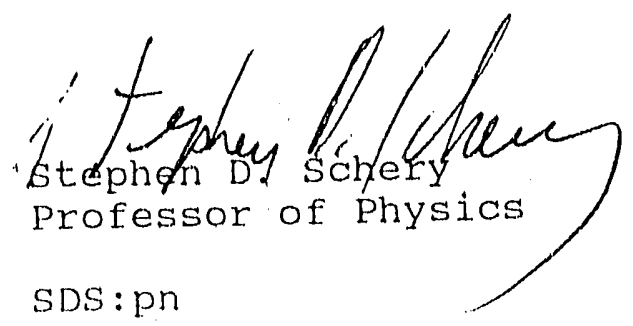


February 8, 1991

Professor Thomas B. Borak

Colorado State University

Department of Radiological Health Sciences

Fort Collins, CO 80523

Dear Tom:

This letter is to confirm our intentions to collaborate with you in the next 2 years on our radon transport projects for DOE/OHER.

After your Ph.D. candidate's (Milan Gadd) visit here this last January 1991, focus of this collaboration is well defined. I can see three areas where collaboration should take place:

1. Provide CSU with one or more versions of our Rn3D code to assist Milan Gadd with interpreting the radon entry data from your test houses.

2. Use your seasonal soil data around the test houses to test Rn3D (validate) with the effects of seasonal variations in ground and air temperatures and soll moisture presence and transport. Transport of energy and moisture are now being added to the Rn30 codes.

3. Co-publish results of above in appropriate journals.

I am pleased that we have these collaborative plans and am looking forward to completing them.

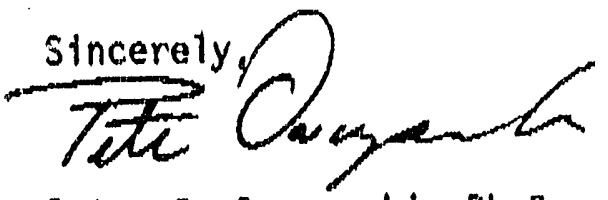

Peter C. Owczárski, Ph.D.

Senior Research Englneer

Applied Meteorology

ATMOSPHERIC SCIENCES DEPARTMENT

PCOsrak

CC: Curtis 01sen, DOE/OHER, ORNL

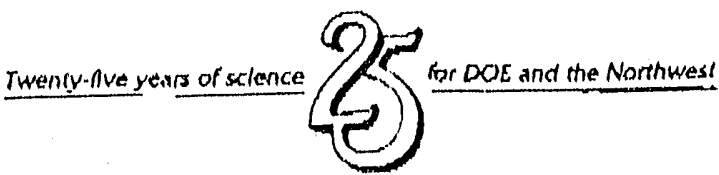




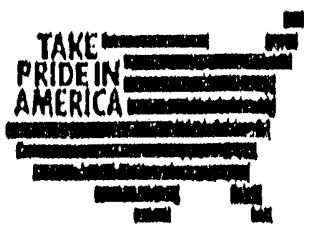

IN REPUY REFER TO

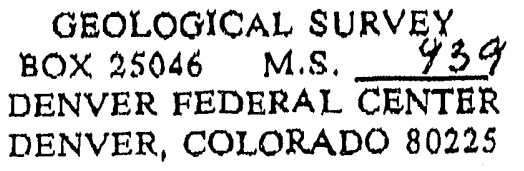

February 8, 1991

Dr. Thomas B, Borak

Colorado State University

Radiological Health Sciences

Fort Collins, Colorado 80523

Dear Tom:

Thank you for suggesting that we may be able to use your radon test facility at CSU for some our our DOE sponsored radon investigations. We would like to discuss further with you the possibility of conducting cooperative studies during the summer of 1991, at the CSU site. These studies are all part of our current DOE contract for evaluating radon transport in the natural environment.

Our interest is to observe the effects of solar heating and near-surface evaporation as driving mechanisms for radon transport. In addition, we would perform some tracer gas (helium) injection studies to determine the transport potential of the local soil.

Because you have spent considerable effort characterizing your test site, the information you have available would greatly enhance the interpretation of our observations. Without question, the proximity of your site to our Denver laboratories is a great advantage for us.

I hope that you find our proposed suggestions will be mutually beneficial for our DOE contracts. Please contact me at your convenience so that we may coordinate our interests in a cooperative program.

Sincerely yours,

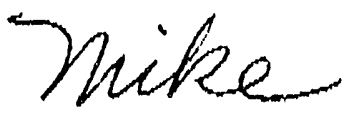

G. Michael Reimer 



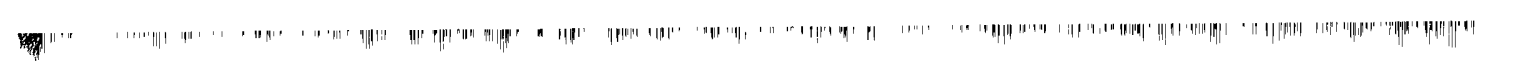

